\title{
Research Environment After COVID-19
}

\author{
(1) Selçuk Nas \\ Dokuz Eylül University Maritime Faculty, Department of Maritime Education and Training, İzmir, Turkey \\ Keywords \\ Research, Environment, COVID-19
}

We all experienced the impacts of the COVID-19 pandemic on the maritime academic research in 2020 and 2021. The most significant of these impacts were the slowing down or stopping of field research activities, creation of new research topics and opportunities, and collaborations using remote access technologies. The Chamber of Marine Engineers, the owner of Journal of ETA Maritime Science (JEMS), has turned remote access technologies into opportunities under the pandemic conditions. The Global Conference on Innovation in Marine Technology and Future of Maritime Transportation (GMC) series, which was traditionally organized by The Chamber of Marine Engineers, was held online on November 18-19, 2021, and organized by the University of Strathclyde (UK), Constanta Maritime University (Romania), and Iskenderun Technical University (Turkey). The GMC'21 conference was attended by more participants than expected. In this issue, Prof. Osman TURAN, Advisory Board member of JEMS, shared his valuable impressions about the conference with our readers in his After Meeting article.

At the end of 2021, when COVID-19 new variant threats continue, we are witnessing a revival of the research climate as restrictions ease off. We also see that the interest in our journal is increasing every day. As a result of this interest, we are sharing interesting original research articles with our readers in the JEMS 9 (4) issue. Hereby, I would like to express our gratitude to the authors, who sent their valuable studies for publication in this issue, our reviewers, editorial board, section editors, and the publisher, who provided quality publications by diligently following our publication policies. 